Tesis. Año 12, 11(12), 63-80

\title{
El arte de escribir, el yo poético y las instancias creativas
}

\author{
Carla Vanessa Gonzáles Márquez \\ yo.carla@gmail.com
}

\section{Resumen}

El trabajo busca determinar la naturaleza de la escritura creativa y qué procesos se cumplen desde el momento en que el escritor ejecuta la labor de construir los universos de ficción que constituyen una obra literaria, ya sea un cuento, una novela o un poema. Asimismo, busca definir la existencia de un yo poético como sujeto discursivo en el universo de la ficción lírica.

Palabras clave: poesía; escritura creativa; muerte; sueño; yo poético.

\begin{abstract}
The purpose of this work is to define what creative writing is and describe the processes since the moment the writer build the fictional universes which is part of a literary work: a tale, a novel or a poem. Also, to define de existence of a poetic "I" as a discursive subject in the lyric fiction universe.
\end{abstract}

Keywords: poetry; creative writing; death; dream; poetic I. 


\section{El arte de escribir, el yo poético y las instancias creativas}

La reflexión crítica acerca del poemario Sueños de Carla, y las tres imágenes que articulan el sueño, la muerte y la vigilia; objetivo del que tratará la tesis para optar el grado de magíster en Escritura Creativa, de quien esto escribe, plantea, en primer lugar, una problemática que es, a criterio de la autora, absolutamente básica a la hora de pensar acerca del proceso creativo en sí mismo y que hemos elegido como tema para el presente artículo. Esto es, la actividad primaria y generadora de nuestras estéticas, nuestras artes poéticas: el acto creativo, cómo se produce, cómo se ejecuta.

La autora de este trabajo cree que, aunque las diferentes corrientes de la teoría literaria, la crítica del arte y otras disciplinas han abordado exhaustivamente la génesis y materia del proceso creativo y, aparentemente se han sentido satisfechas con los resultados o planteamientos esgrimidos en estas últimas décadas, la interrogante siempre quedará abierta al debate ya que este acto que nos enriquece como seres humanos y sociedad es harto complejo y profundo. De tal modo que, a lo largo de la historia de la humanidad, a quienes se han dedicado a esta labor se les ha comparado con magos, con genios o hasta se les ha señalado como portadores de maldiciones.

En algún momento de la historia se creía que los escritores y a los artistas eran una suerte de seres dotados de condiciones especiales que, tras un momento de arrebato o ensoñación producto de un estado mental determinado, podían "recibir la visita de las musas" que les traerían el impulso para componer una obra literaria que satisficiera su sed de conocimientos sobre el mundo en el que vivían y sobre sí mismos. Este proceso, naturalmente, debía estar más allá de todo lo que encerraba la lógica y el razonamiento. O sentarse frente a la ventana una diáfana tarde o frente al mar o en la soledad de un paraje y esperar que llegara la diosa inspiración o la musa que impulsara al espíritu creativo para componer una historia de ficción. La poesía, las artes poéticas, eran entonces una actividad a la que solo unos cuantos podían 
dedicarse. De hecho, y como lo dijo Roberto Juarroz, el poeta es "un místico irregular, un extraño místico que habla aunque sepa que el silencio está en la base de todo o es la base de todo" (Juarroz, 1992, pp. 25-26)1, entendiéndose el silencio como un estado especial que les permite la libertad dentro de la esfera de lenguaje en que crean. Pero crear implicaba no solo imitar al modo aristotélico, la realidad, sino representarla de acuerdo con el sentido de la percepción del ejecutante de la obra, hacerse preguntas respecto a ella y, si sentía que se podía, esgrimir resultados, esbozar posibilidades gnoseológicas sobre sí mismo, sobre sus pares, sobre el universo entero, el todo; y para ello, no solo bastaba la inspiración como mecanismo, sino aplicar un conjunto de lógicas racionales que esbozara una técnica comunicacional diferente a la convencional, un andamiaje estético que hiciera posible que una historia sea narrada o un poema sea construido, un canto o una imagen sobre lienzo sean plasmados.

Se trataba entonces de explicar el mundo, de entenderlo y para definir su función o rol dentro de él. El hombre trató de hallar mecanismos que pudieran darle respuestas. Tratar de hallar un puente entre el hombre y la realidad era una tarea difícil. Este se sirvió de la palabra, entonces, para llegar a ella y representar su mundo; al ejercer este acto, ya se estaba creando una relación indisoluble. Octavio Paz ha dicho que el hombre es un ser de palabras ${ }^{2}$, y es a través de ellas que el hombre encontró la herramienta perfecta que unió esos dos mundos. La relación entre la palabra y las cosas adquiría ribetes extraordinarios. El crítico Northrop Frye decía a este respecto que:

en su origen, este procedimiento debió de ser casi mágico: la magia suele convenir en que la conexión causal entre una palabra y una cosa, un nombre y un espíritu, y el esfuerzo poético de colocar las palabras apropiadas en el orden apropiado podría tener efecto en el mundo externo. (1996, p. 103)

Y esta manifestación puede también verse reflejada en otras disciplinas además de la escritura. En una actividad aparentemente representativo-reproductiva de la realidad como la fotografía, por ejemplo, está el ojo del ejecutante, el fotógrafo; quien a través de la calibración de la luz, la obturación, la elección de la sensibilidad de los receptores de las imágenes (la emulsión de plata en las películas o ahora los píxeles) impone su propio lenguaje de interpretación. La fotografía ya no es más una labor técnica mimetista, ha pasado a ser una forma artística que ha construido su propio lenguaje sublimado, trascendente al que utilizamos todos los días, que comunica más allá de una racionalista reproducción de imágenes.

De hecho, "lo que se nos ocurre" o lo que nos inspira es el primer combustible, nuestro big-bang que alienta a echar a andar el carro de la creación. Pero 
en el resto del proceso el escritor deberá desarrollar y utilizar todas su habilidades técnicas y cognitivas para dirigir su obra hacia donde pretende que esta llegue y para que finalmente alcance el impacto deseado en sus lectores y se inserte en su tradición. Ezra Pound describía estos dos importantes elementos en la creación como el "intelecto y la emoción", que son las dos herramientas con las que el creador logrará su éxito. Este éxito, claro está, entendido como un proceso de continuidad o de ruptura con su medio. Porque la tradición es una instancia ineludible en la vida de un escritor, la tradición es el medio en el que este nace, crece y se desarrolla y a través del cual, explícita o implícitamente, se ha influenciado. Este es un factor innegable, así pretenda irse contra ella o simplemente negarla, o pretender que no existe. Emily Dickinson, la extraordinaria poeta norteamericana pareciera ser el caso por el que alguien pudiese sustentar que lo que se ha señalado líneas arriba, no es cierto. La escritora, como se sabe, casi no salió de su casa ni de su pueblo durante toda su vida. Sus poemas fueron descubiertos después de su muerte, guardados en un cajón y cuando finalmente alcanzaron las imprentas y luego llegaron a los ojos de sus millones de lectores, sorprendió por su altísima calidad y propuesta estética. Sin embargo, eso no significa que la autora haya vivido divorciada o ignorante de su tradición; su formación académica y luego su dedicación como docente sin duda le permitieron tener acceso a literatura escrita por poetas y escritores clásicos y de su tiempo; fundamentales para la construcción de su propia arte poética, considerada fundamental en la literatura norteamericana del siglo XIX.

Esto plantea la siguiente duda: ¿podemos todos ser artistas? ¿Podemos todos dedicarnos al arte de la creación? ¿Se trata tan solo de expresarnos a través de una estética sobre lo que conocemos, sobre lo que percibimos, sobre lo que sucede en nuestro alrededor? ¿Acaso el arte no es la plasmación de esa necesidad que como fuego que no se apaga nos atiza a todos con preguntas, con deseos, con inquietudes respecto a nuestra esencia y existencia? Durante los últimos dos siglos, la literatura había pasado a ser un conjunto de obras de entretenimiento de cortesanos y pequeños círculos. Otras disciplinas como la filosofía y la teología habían tomado su primigenia posta y eran ellas quienes se encargaban de los conceptos del mundo. Se escribían novelas y cantares de gesta, universos de ficción dedicados a algún monarca o autoridad. Pero después expandió una vez más su radio de acción hasta extender su influencia e intervenir, inferir en otros aspectos de la sociedad y la cultura humanas. Antaño había nacido de los mitos y las leyendas que los sumos sacerdotes, oráculos o seres elegidos, contaban y cantaban ante su público embelesado y hambriento del conocimiento fundamental. Luego las comunidades crecieron y se volvieron sociedades, naciones; surgieron las luchas por el poder, los diferentes sistemas políticos y económicos, las religiones, los acontecimientos históricos como invasiones, guerras y tratados y hasta los desastres naturales 
que también eran materia prima, registros que los poetas y narradores tomaron para reflexionar a través de un sistema codificado de significaciones. Todos, de hecho, elaboramos nuestra propia interpretación de la realidad. No nos conformamos con ella y nos surge la necesidad de ir más allá, de reinventarla y reinventarnos a nosotros mismos con la esperanza de hacerlas más satisfactorias, ricas. No nos conformamos con lo que se nos ha dispuesto para la vida y vamos más allá. Y para llenar esa insaciable e imperecedera necesidad que irá con nosotros hasta el fin de los tiempos, unos toman la posta de convertirse en artesanos de la ficción y los otros, los receptores. Los otros elementos integrantes de este poderosísimo y complejo mecanismo creativo, pasan a ser quienes hacen posible estos universos paralelos al del mundo real. No se podría dar de ninguna forma un proceso creativo si este no se activa a través de sus receptores. Juan Ferraté decía que gracias a estos se daba un proceso de formalización de los datos de la obra de arte, de la experiencia vital del artista, y en síntesis, "un proceso de formalización íntima" (Ferraté 1957, p. 17), que es en donde todos los datos se vuelcan y adquieren un sentido definitivo que se traslucirá en una obra de arte.

Sin embargo, para convertirse en artista hace falta más que conocer las herramientas básicas de la comunicación. El autor debe tomar dichas herramientas y crear una nueva forma de expresión, una lengua que haga posible el desarrollo de su producto como artístico, ya que los universos creativos que va a plasmar en su trabajo así lo exigirán. Las generaciones que comenzaron con la vanguardia lo entendieron así, de modo que pretendieron hacer del creador una suerte de oráculo transmisor de ese supremo conocimiento, a través de aquellas nuevas y superiores formas de comunicación. Rimbaud diseñó así su teoría del vidente, el resto de los simbolistas y luego los surrealistas vincularon los aspectos sagrados al subconsciente, al de la realidad con que el hombre se fusiona alcanzando una forma totalizadora y totalizante. Durante el proceso de vanguardia se cambia también el entendimiento sobre la poesía del poema. Este último ya no era solamente un conjunto de sonidos que estaban por encima de su contenido, sino que la construcción de la imagen aparece como un componente esencial que va más allá de la forma misma y para construirla habrá que desarrollar una técnica. De este modo van surgiendo otras artes poéticas derivadas de estos pensamientos en que el papel del creador es otro, se maximiza en busca de ese absoluto (acaso volviendo a esa su condición primigenia de oráculo o sumo sacerdote de gran influencia en su comunidad) y la obra de arte adquiere un enorme protagonismo frente a su realidad. Ahora la poesía puede torcer su destino, apropiarse de él, ser un todo.

En los años 50 y 60 y bajo la influencia, sobre todo de la literatura inglesa y norteamericana, surge la poesía conversacional y contestataria, la poesía como técnica que se planta cara a cara con su realidad y la provoca: surgen entonces 
el manifiesto, la consigna. La poesía peruana, sobre todo la de la generación del cincuenta, recoge algunas de estas propuestas y las cristaliza en trabajos líricos de mucha fuerza y potencia. Un ejemplo de ello es el poema "La Huelga" de Alejandro Romualdo de la que citamos un extracto:

Ya sé que tú no puedes comprender por qué

Por qué me emociona una cosa tan "común" como una huelga:

Una huelga es más honda que un espejo,

Una huelga es más pura que un vaso de agua.

Una huelga refleja mil deseos y privaciones,

Largos años de sufrimiento,

De pan frío,

De lecho frío.

Una huelga clama una sed infinita,

Una infinita sed de justicia.

(Romualdo, 1986, p. 108-109)

Y la poesía, entonces, se vuelve una herramienta de lucha, de reivindicaciones y el rol del creador adquiere otra forma. Volviendo al caso citado de los escritores peruanos de la generación del 50, por ejemplo se hablaba de la "poesía pura" y la "poesía social". Los primeros supuestamente conservaban los aspectos subjetivos del yo poético y sus universos ficcionales y los segundos asumían la poesía como una herramienta política y de compromiso. En el siglo anterior, influido por el positivismo, la poesía reflejaba como un espejo los procesos sociales; ahora se revela, se sublimiza, luego baja al llano y provoca; acaso narra también los sucesos de su tiempo: revoluciones, protestas, huelgas masivas, pero no de un modo simplemente descriptivo, sino elusivo.

Sin embargo, en la historia de la literatura es casi una obligación detenernos en la segunda mitad del siglo XIX en que se comenzó a reflexionar sobre los vasos comunicantes entre el escritor y la obra literaria, el escritor y sus lectores, el creador, lo creado y su papel frente a los procesos sociales e históricos de su tiempo. El creador es percibido como otro dios que ya no será el proyector de la historia sino su cuestionador, su transgresor, el que lleve todo al límite. La poesía es la vida misma, lo primigenio y lo de su tiempo, la naturaleza y la historia; y así lo entendieron autores como Lezama Lima o Rilke cuando describieron sus artes poéticas. La realidad se procesa, se vuelve irrealidad (como lo dijo Juarroz) y luego llega al lector como expresión máxima, universal que lo condensa todo. La literatura, a diferencia quizá de las ciencias, no puede explicarse desde el punto de vista meramente utilitario, pero sí desde una perspectiva totalizadora: trabaja con una de las herramientas que nos distinguen de todos los otros seres vivientes: un sistema organizado de significaciones por las cuales nos comunicamos. 


\section{El sujeto narrativo y el yo poético}

Para el caso de la poesía, el punto anteriormente expuesto deriva necesariamente en una segunda reflexión que se alza como un antecedente al proceso de explicar los procesos creativos para la construcción de un poema, y más específicamente y para nuestro caso, para explicar los mecanismos en que este se produce: nos referimos a la naturaleza y construcción de la entidad discursiva que nos habla desde el universo de ficción creado por el escritor. Un relato, una historia narrada, contiene diversas entidades que interactúan y hacen posible su consecución y funcionamiento. El autor, al escribir su obra narrativa, como el poeta al escribir sus versos, desarrolla un conjunto de instancias discursivas que, independizadas de él, harán posible comunicar la obra a quienes la lean.

En ese sentido, el planteamiento que se pretende desarrollar a continuación intentará responder la siguiente interrogante: si como sucede en la narrativa, aceptamos la existencia de un sujeto narrativo que no es el autor del texto, o el sujeto empírico del mundo real que es el que se comunica con el que lee y que se disocia del autor real una vez que el cuento o la novela han sido creados, ¿lo mismo sucede en el campo de la poesía?

Si hacemos un repaso a través de las diferentes corrientes teóricas de la narratología de los últimos 50 o 70 años, veremos que los postulados académicos de los representantes de las más importantes corrientes de la teoría literaria (Gerard Genette, Tzvetan Todorov o Roland Barthes, por ejemplo), expresan que dicho sujeto no se refiere al autor de la obra literaria que la ha creado siguiendo los procesos de inspiración y cognición, sino al ente, a la entidad quien narra la historia, eso es, al sujeto narrativo.

Gerard Genette, por ejemplo, hablaba de un sujeto de la enunciación al que le denominaba "voz" y que era una especie de agente textual que conduce o despliega a través de su narración los hechos del relato. A esta entidad la dividía en tres tipos: narrador heterodiegético, homodiegético y autodiegético según el conocimiento o sabiduría que tuviese respecto de los acontecimientos del relato y según el enfoque de este.

A partir de los postulados de este teórico francés se establece que entre autor y lector existen más de una entidad que se encarga de que el proceso comunicacional entre ellos se lleve a cabo. Hay un emisor o narrador, hay un mensaje, y también un receptor. Seymour Chatman en su Historia y discurso nos habla de narrador, un narrador implícito, un narratario, un lector implícito que antecede al lector de carne y hueso; todas ellas entidades presupuestas por la ficción del relato. 
Esta entidad discursiva en el campo de la literatura en general es también construida con base en la elaboración de un lenguaje artístico por parte del creador, el medio comunicacional por el cual el escritor ha buscado, desde la antigüedad, explicar su realidad, ampliarla, negarla, mejorarla y sobredimensionarla si se quiere, más allá de lo que él hubiera querido para sí mismo. Como lo expresó Mario Vargas Llosa, se trata de escribir "sobre aquello que no existe en realidad pero que quisiéramos que existiera"; maravillosos y de vidas que tal vez nunca el autor real ni el lector vivirá. En ese camino, en este proceso, el sujeto narrativo surge como una entidad que logra disociarse del que ha creado el relato y nos introduce en su mundo, haciendo que los lectores se desdoblen también a través de un lector presupuesto y un receptor de la narración, el llamado "narratario".

\section{Universos de ficción en la narración y la poesía}

Tanto la narrativa como la poesía son instancias igual de complejas. Encierran un universo ficcional intrincado en el que el autor es el constructor de una realidad paralela y el lector el reconstructor de ella una vez que el libro llega a sus ojos. De hecho, el universo que reconstruya el lector no será el mismo que el que prefijó o imaginó el autor y este aspecto será determinante en una obra creativa de ficción.

En una obra narrativa puede existir un único sujeto narrativo, múltiples sujetos; dicho sujeto puede formar parte activa en la historia, es decir, ser un personaje de la o las historias, puede también no tomar parte de la historia, pero sí ser testigo en primera línea o un testigo complementario del relato; puede, también, ser un narrador que no sea parte de la historia pero que conozca de plano todos los aspectos, lugares, hechos y personajes de dicha historia, una suerte de dios omnipotente y omnipresente en la historia narrada.

Del mismo modo, cuando enfocamos nuestro ojo investigador y crítico sobre un poema, encontramos que hay una voz lírica que es la que se comunica con el lector a través de los versos; una voz que nos habla, ya sea desde el lenguaje sencillo y conversacional o discurriendo a través de imágenes construidas con los recursos que nos otorgan las figuras retóricas, las cuales será el lector, a través del receptor poético, quien la reconstruya para así establecer ese vínculo estético que es el ciclo de la poesía y que forma parte del universo de la ficción.

Esta voz lírica ha sido sujeta a mucha deliberación en el campo de la crítica literaria y filosófica. Por ejemplo, en la época del romanticismo alemán se postulaba que la voz poética equivalente al sujeto narrativo, al narrador tenía un carácter marcadamente subjetivo y que apuntaba a una suerte de introspección, a un viraje hacia el "yo" y que se traslucía en poemas que derivaban de las experiencias de su creador. Es decir, no se aceptaba que había una disociación entre 
el autor real de los poemas y la voz narrativa de estos. Con el advenimiento de la modernidad desde Baudelaire y sus propuestas estéticas revolucionarias (sus nuevos conceptos de belleza de lo tradicionalmente rechazado por no bello, como las de Baudelaire y sus "correspondencias" que no eran sino una propuesta multisensorial de alcanzar un todo); las de Rimbaud y su enfoque hacia el "otro"), se dio paso a la poesía moderna y al replanteamiento de las entidades que crean físicamente el poema y que viven en él condiciéndonos a su universo lírico propio.

Estas referencias hacen necesario un examen sustentado en diversos marcos teóricos que las definan y que sienten las bases para el desarrollo de una reflexión crítica respecto de las entidades que forman parte de estos poemas: ¿existe solo una voz poética en el poema? ¿Cómo en la narrativa pueden coexistir varias, a modo de "personajes líricos"? Los poemas homéricos podrían ser un ejemplo que avive y responda esta interrogante. Aristóteles dividía la poética (entendida como concepto totalizador de una obra o género literario) en épica, lírica y dramática y en cada una de estas instancias y de acuerdo con el enfoque, podían coexistir "personajes" o sujetos discursivos múltiples, además del "narrador". Mucha agua ha corrido bajo el puente al momento de determinar la existencia y las características de estas figuras textuales y sus relaciones dentro del proceso de dación y recepción de la obra. Lo cierto es que, la mayoría de teóricos coincide en aceptar que estas entidades discursivas se cristalizan una vez que el autor ha configurado su universo ficcional. A decir de Juan María Calles: una vez que el discurso ficcional está establecido, enunciador y receptor forman parte de un "juego" o "pacto" que se justifica dentro de una situación histórica. De este modo:

La diferenciación entre Autor y Narrador tiene como conditio sine qua non el reconocimiento del discurso literario como discurso ficticio. Del mismo modo, en el discurso poético, el reconocimiento de la fictivización permite la diferenciación entre Autor y hablante lírico. (1997, p. 144)

Del mismo modo, este necesario repaso historiográfico por la tradición poética permitirá entender en qué parte de dicha tradición se puede situar el poemario que será sujeto de la reflexión crítica por parte de la autora de este artículo y si esta expresa alguna propuesta generacional. ¿Rompe esta obra con su tradición?, ¿se adscribe a ella?, ¿en qué lógica se ubica respecto de la tradición que la precede o la acompaña? O ¿cómo se manejan las tensiones discursivas? Rainer María Rilke decía que la tradición es una memoria discursiva, de modo que cualquiera que pretenda crear tiene que experimentar desde la tradición.

En este sentido, lo que se pretende realizar en la reflexión crítica es, en primer lugar, reconocer y conocer la propia tradición, no solo en el campo del 
trabajo poético propio, sino de la poesía en general, entendido a la manera de Octavio Paz, ese crisol totalizador que convierte un conjunto de palabras en poemas, en obras literarias, en objetos producto de la creación artística. En este sentido, la reflexión crítica de quien esto escribe se orientará a explorar los mecanismos cognitivos y subjetivos que en el interior de la mente del artista se activan al momento de componer, en nuestro caso, un poema, un conjunto de poemas agrupados en un libro.

Así, del mismo modo que el sujeto narrativo, el sujeto lírico no necesariamente coincidirá o estará de acuerdo con lo que sienta o quiera el escritor del poema; sin embargo obtendrá, una vez creado el poema, la libertad suficiente como para convertirse en la gran voz que exprese la totalidad del poema. El sujeto lírico recogerá herramientas que desde la actualidad han vinculado a la literatura con otras expresiones artísticas como la música, el ritmo. Abraham Valdelomar hablaba del ritmo universal que rige todas las cosas y de una de sus clases que es una suerte de ritmo supremo que es cristalizado en la poesía. En ese sentido, el sujeto poético será la entidad que será capaz de atrapar esta tonalidad fundamental y usarla para construir sus universos líricos a través de las herramientas retóricas ya conocidas.

\section{E1 sujeto lírico y el proceso creativo en el poemario "Sueños de Carla"}

El poemario Sueños de Carla, es un trabajo que fue escrito y publicado en Internet en el año 2002, se compone de 23 poemas, numerados en romanos, algunos de ellos con título propio. En cada uno de ellos hay una voz que se comunicará con nosotros y se introducirá en un viaje a través de un proceso onírico profundo en el cual la muerte, como en una suerte de mímesis tocará su puerta a modo de un elemento destructor de su esencia, pero a la vez catalizador, cuestionador y, finalmente, transformador. El yo poético renacerá de sus propias cenizas, si bien no triunfante, sí transformado, otro, dispuesto a retomar el camino de su evolución vital.

El poemario obedece a una estructura en que tres imágenes principales son las que dominan: la vigilia, el sueño y la muerte. La imagen del sueño es la figura retórica dominante. El sueño se erigirá como un tipo de muerte por el que este atravesará, entendiéndose la muerte como un proceso de acabamiento emparentado con imágenes propias de la tradición bíblica del juicio final (tormentas, cataclismos, maremotos, destrucción masiva de las cosas) y de transformación. El sujeto lírico es la entidad discursiva principal que anunciará desde el poema I hasta el XXIII el cambio de su condición esencial, desde la vigilia al mundo onírico mortal para luego regresar a la vigilia, en una suerte de viaje circular. Para graficar estos postulados citaré cuatro de los 23 poemas que reflejan los tres momentos por el que el sujeto lírico atravesará a lo largo del poemario ${ }^{4}$. 
Comenzaremos por el primer poema (Poema I), el cual presenta al hablante lírico situado en una hora en el tiempo en que aún no hay que "decir las buenas noches"; es la antesala de ese viaje que dicho sujeto discursivo realizará hacia el sueño y como un primer gran bloque dentro del poemario:

En la hora en que aún no hay que arroparse,

ni decir la buenas noches,

la lucha del ojo es cruel;

remalazos de voces y memorias

Los doblegan implacables

Es, un momento en el tiempo que se corresponde con la vigilia, pero las voces y las memorias inducen al yo poético al sueño. El mundo de la vigilia es descrito como un universo de contradicciones que afligen al hablante lírico.

Este poema presenta también otra característica importante: el hablante lírico se dirige a un "tú" o a un interlocutor: y no te das cuenta/ que a tu lado están sentados/dándote de beber la sed que nunca tuviste. ¿Se estará refiriendo a su interlocutor como único receptor de su discurso?, ¿o estará dirigiéndose a todos los lectores? Este aspecto será abordado en el trabajo de tesis de la autora.

Luego vendrá un segundo grupo que comprenderá desde el poema II al poema XVIII. Dicho bloque representará la entrada y tránsito del hablante lírico al mundo de los sueños.

Es importante señalar en esta parte que la imagen de la muerte asociada con el sueño se recoge de la tradición del barroco español que emparentaba la imagen del sueño como una forma de la muerte. El conocido poema de Francisco de Quevedo, "Al sueño" será puntal, en el trabajo de tesis para abordar esta visión estética del mundo onírico: Pues no te busco yo por ser descanso,/ sino por muda imagen de la muerte.

El barroco español es esa luminosa etapa de la literatura universal en donde el tema del sueño, la vida y de la muerte se manifiestan acaso con mucha más fuerza que en otros momentos. Como se sabe, los aspectos morales estaban marcadamente presentes en muchas de las representaciones líricas, narrativas y teatrales del barroco español, a veces de forma subrepticia, bajo los carices burlescos e incluso rebeldes y críticos de las temáticas que sus autores abordaban. El influjo de la enseñanza heredado de las fábulas, del reflejo de que cada acto tiene sus consecuencias, estaba profundamente marcado en las obras literarias de sus representantes. Podemos citar como modelos los Sueños o Política de Dios y gobierno de Cristo del ya mencionado Quevedo, o La vida es sueño, de Pedro Calderón de la Barca. La imagen de la muerte era algo que preocupaba al hombre del siglo XVII fuertemente influenciado por los dogmas de las religiones cristianas y herederas del aún más fuerte influjo venido del medioevo: la 
muerte, el juicio final, la salvación de las almas. Una preocupación constante de esos tiempos que reflejó en su literatura era la naturaleza de la vida del hombre y las consecuencias de sus actos transparentados en una muerte que puede resultar en una transformación y el paso a un estado superior del que se ha llevado en la vida terrenal. Esto hizo reflejar el estadio de la vida como un momento fugaz, pasajero, momentáneo, ya que se nace para morir y se comienza a morir ni bien se nace. A la vuelta de la esquina, esperaba la muerte como paso a la eternidad en el paraíso o a la condenación.

Otro aspecto importante tomado del barroco y su imagen del sueño es el tema de la premonición, que ya viene también como heredada de la mitología griega y de la obra de Dante Alighieri. En el sueño se delibera, se reflexiona a través de las imágenes y símbolos representados que pueden indicar el camino a seguir al sujeto lírico, para alcanzar la transformación ansiada, la liberación de su condición anterior. Las imágenes caóticas y destructivas se toman como símbolos del final y la condenación, pero también de retos a superar, siempre que el sujeto narrativo o hablante lírico posea ciertas cualidades morales, cumpla con ciertos requisitos.

En el caso del hablante lírico de Sueños de Carla, este necesita pasar por este estadio del sueño para superar el dolor que le acongoja el vivir y que es descrito en los otros poemas de este segundo bloque. Las decepciones amorosas reflejadas en referencias a un interlocutor, por ejemplo, reflejarán que este hablante lírico, que es femenino, necesitará superar a través de un violento proceso transformador que solo podrá ocurrir en el mundo onírico. En la tesis que la autora de este texto está preparando, se abordará con más detalle el aspecto de cómo estos estadios afectarán al hablante lírico y cómo y mediante qué técnicas poéticas este expresará las sucesivas transformaciones que irá describiendo.

De este segundo bloque en el poemario quisiéramos destacar y citar el poema "Sueño de Lázaro" como ejemplo de otro personaje lírico que cohabita con el sujeto lírico o hablante lírico en el universo narrado en el poemario. Es este ahora, el que se comunica con el lector del poema:

La luz es una risa lustrosa y falsa que golpea mi casa de cortinas

La vida ahora ya no es ese estadio en el que añoramos permanecer necesariamente. La muerte es una necesidad para pervivir, y arrancársele de ella es nocivo:

quiero ser agua entre las nubes, quiero ser sombra entre las ramas, no quiero tus dientes ni tus perlas, 
ni la alegría de los que se creen vivientes

y me abrazan.

El remate del poema es la negación del mito bíblico de Jesucristo resucitando a Lázaro. El personaje Lázaro no quiere abandonar el estado del sueño que es la muerte:

Di recuéstate Lázaro,

No te levantes.

En el trabajo de tesis, otro de los objetivos a dilucidar es resolver cómo este otro personaje discursivo influenciará en el hablante lírico principal respecto a su visión y perspectiva sobre la vida y la muerte. ¿Estará este otro personaje pasando por un proceso transformador como nuestro narrador lírico? ¿Será tan solo un personaje de paso, uno de los muchos recuadros de imaginería que presenta el poemario? Y también se abordará qué relación y qué efectos tiene la concurrencia de las imágenes bíblicas en la construcción de los agentes líricos que habitan en el poemario.

Desde el poema XIX al XXIII se retorna a la vigilia en un tercer y último bloque en el poemario Sueños de Carla. En el poema XXI, que citaremos como ejemplo, veremos cómo el hablante lírico acepta la soledad de la que ahora padece, pero el dolor que le ha acompañado a lo largo de su vida en el poemario se ha transformado en algo que ya no destruye, sino que se acepta y se incorpora como parte de la vida.

Allá la mañana

Y la agónica estrella atando jamases

Entre la frente y la espalda de alguien

Que sólo sabe soñar.

Se ha muerto pero no se ha muerto. Se ha muerto y se ha resucitado a través del sueño, pero no se ha terminado con su existencia sino que se ha enriquecido de alguna manera enfrentando al caos y al dolor dentro del mundo representado en la fase onírica. El yo poético ha luchado contra sus propios demonios y ha bajado hasta el infierno, y ha salido airoso. Quedará dilucidar en la tesis, de qué manera subjetiva y estética estas acciones se han realizado con éxito, $\mathrm{y}$ cómo estéticamente la preeminencia del hablante lírico hace posible que se dé curso a este proceso transformador, de qué manera las otras instancias líricas que van apareciendo o son descritas en el poemario consolidan dicho rol, dicho viaje lírico de la vigilia al sueño y luego a la vigilia y cómo el proceso creador consciente y deliberado fue determinante para su ejecución. 


\section{Notas}

1 Roberto Juarroz (1992). Poesía y realidad. Valencia, Pre-textos.

2 Octavio Paz. El arco y la lira. México, Fondo de cultura Económica 1982, pp30.

3 Mario Vargas Llosa (2002). "La pasión de escribir”. Coloquio que ofreció MVLL en la Universidad de Piura. Piura, 18 de diciembre.

4 Dichos poemas podrán consultarse en el anexo de este artículo.

\section{Referencia}

Bachelard, G. (2003). El agua y los sueños. Ensayo sobre la imaginación de la materia. México: FCE.

Calles, J. M. (1997). La modalización en el discurso poético. Tesis doctoral. Universidad de Valencia. Recuperado de www.cervantesvirtual.com/descargaPdf/la-modalizacion-en-el-discurso-poetico--0/

Cohen, J. (1974). Estructura del lenguaje poético. Madrid: Gredos.

Eliot, T.S. (1959). Sobre la poesía y los poetas. Buenos Aires: Ediciones Sur.

Gallegos Díaz, C. (2006). Aportes a la teoría del sujeto poético. Espéculo, 11(32). Recuperado de http://www.ucm.es/info/especulo/numero32/sujepoet.html

Friedrich, H. (1959). Estructura de la lírica moderna. Madrid: Seix Barral.

Frye, N. (1996). Poderosas palabras, La Biblia y nuestras metáforas. Barcelona, Muchnik editores.

- (1964). El hombre y sus símbolos. Buenos Aires: Paidós. Recuperado de https:// drive.google.com/file/d/0Bw_RU_VsrEHuX1VXQkMzb3VvX0U/view

Paz, O. (2012). El arco y la lira [versión electrónica]. Recuperado de http://estrategiadidactica.files.wordpress.com/2012/09/paz-octavio_-elarco-y-la-lira.pdf

-. (1974). Los hijos del limo. Barcelona: Seix Barral.

Ricoeur, P. (2001). La metáfora viva. Madrid: Ediciones Cristiandad y Editorial Trotta.

Rilke, R. M. (2010). Cartas a un joven poeta. Recuperado de http://www.librosenred. $\mathrm{com} /$ triviaregalos/1a2s3d4f/6515-cartas\%20a\%20un.pdf

Romualdo, A. (1986). Poesía íntegra. Lima: Viva voz editores.

Sábato, E. (s.f.). El escritor y sus fantasmas. Recuperado de https://docs.google.com/ viewer?a=v\&pid=sites\&srcid=ZGVmYXVsdGRvbWFpbnxhcnRpc3RpY28zYWUOfGd4OjY2ZDViYzIwZDI1MmViODg

-. (1988). Heterodoxia. Madrid: Alianza Editorial

Wellek, R. \& Warren, A. (1966). Teoría Literaria, Madrid: Gredos. 


\section{Anexo (poemas citados en este trabajo)}

\section{I}

En la hora en que aún no hay que arroparse, ni decir la buenas noches, la lucha del ojo es cruel;

Remalazos de voces y memorias

Los doblegan implacables, Y a la caída del telón

Todo el mundo corre a esconderse.

En el fragor de las calles

Y las plazas

hay murmullos,

$Y$ las plegarias

de padrenuestros

y de prestado

merodean,

Con el beso en una mano

Con el puñal en la otra,

$\mathrm{Y}$ no te das cuenta

que a tu lado están sentados

dándote a beber la sed que nunca tuviste. 


\section{V}

Veo girar el mundo como una bala sin rumbo,

Dormida de espaldas a la luna

La arena toma la forma del aire.

De nada sirve beberse lo que ya se ha derramado

Porque la piedra no quiere ser montaña

Y el ladrillo se ha rebelado contra el muro.

Una maraña de arterias se enreda entre cables y ojos como pantallas.

Quiero una cama blanda,

Un silencio de ataúd con dos puertas por si revivo,

Un túnel clandestino por donde ir pasando mis venas

Y mis glándulas,

Escapar, escapar de la rueda que aplasta el diente contra el diente,

Para regalarte un racimo de brazos y tripas

Como prueba de mi amor.

Nadar, nadar dando brazadas de gigante,

entre guitarras y peces de bocas como inodoros,

y tocarle la espalda al agua en esas tierras

Donde se muere más temprano,

Lenguas calientes que violan la paz de la estrella:

Quisiera arder en el brasero sin enredar el pie

En este cordón de púas y lentejuelas

En cuyos pliegues se revuelve el pensamiento

En un silencio sordo de números

$\mathrm{Y}$ teclas. 


\section{Sueño de Lázaro}

La luz es una risa lustrosa y falsa que golpea mi casa de cortinas, y de mantas enormes en que mi cuerpo toma la forma que tú quieras: la de un ángel, un alero y su cabestrillo en el que un dios se puede sentar, una cajita para guardar tus sueños.

Pero la luz es una piedra gigante y despiadada que se mete en mi cuarto, arroja sus pliegues, incendia sus ángulos agudos, golpeando mi cara.

Quiero ser agua entre las nubes, quiero ser sombra entre las ramas, no quiero tus dientes ni tus perlas, ni la alegría de los que se creen vivientes y me abrazan.

Échame de esta torre en que fue asesinado el último príncipe, échame sortilegio que me arropas entre la tierra y el cielo, Di recuéstate Lázaro, No te levantes. 


\section{XIX}

Escoges el papel más límpido,

El más fino lapicero,

Y me escribes una carta tan elegante,

Tan amable,

Y cual frutero trepas al árbol

Y escoges las más bellas palabras,

Los adjetivos más precisos,

Las más espléndidas citas,

Para quedar bien,

Para cerrar delicadamente el libro

Que no se abrirá jamás.

Afuera ves la tarde brillar

Y no sabes por qué te mira pálida y con aire de tristeza;

Y allá la mañana en la otra orilla,

Allá la mañana

Y la agónica estrella atando jamases

Entre la frente y la espalda de alguien

Que sólo sabe soñar.

(Una sonata de fuego comienza a posarse en mis incendios). 